\title{
POST-IMMOBILIZATION WRAPPING OF PREY BY LYCOSID SPIDERS OF THE HERBACEOUS STRATUM ${ }^{1}$
}

\author{
By Jerome S. Rovner and Susan J. Knost
}

Department of Zoology, Ohio University, Athens, Ohio 4570I

The use of silk for wrapping prey is generally associated with those spiders that construct trapping webs; nevertheless, there are indications in the literature that wandering spiders sometimes use silk for this purpose. In some of the latter cases the silk is applied after the prey has been subdued by biting, a use corresponding to that of the diguetid and linyphiid web-weavers studied by Eberhard (1967). Post-immobilization wrapping in the latter two families was suggested to prevent the prey from falling out of the web during subsequent attacks (ibid.), and in araneid spiders to have the same and additional roles, depending on species and prey size (Robinson et al., 1969). The function of this behavior in the non-web-weaving ctenids (Melchers, 1963), theraphosids (Eberhard, 1967), and lycosids (Rovner, I97I) remained unknown and was the subject of the present study. Our findings suggested that post-immobilization wrapping by wandering spiders serves the same general function that it probably does in web-weavers - to prevent prey from dropping from the spider's elevated location down to the ground whenever it is released from the chelicerae during feeding, grooming, or subsequent capture attempts.

\section{METHODS}

We observed individuals of Lycosa rabida Walckenaer (females $={ }_{12}-19 \mathrm{~mm}$ ), Lycosa punctulata Hentz (females $=13-15 \mathrm{~mm}$ ), and Schizocosa crassipes (Walckenaer) (females $=8$-10 $\mathrm{mm}$ ) for the presence of and nature of prey wrapping. Whereas $S$. crassipes was collected during spring on forest leaf litter, both species of $L y \cos a$ were found in grassy fields, L. rabida during the summer and L. punctulata during early fall. The spiders were collected in Athens Co., Ohio, USA.

Spiders were housed individually in plastic cages $(70 \times 125 \times$ $70 \mathrm{~mm}$ high) with water available ad lib., and given mealworms (larvae of Tenebrio molitor) for maintenance feedings. Laboratory

\footnotetext{
${ }^{1}$ This study was supported in part by National Science Foundation Grant (SB 35369 to J. S. Rovner.

Manuscript received by the editor September 20, 1974.
} 
temperatures averaged $25.8 \pm 2.7^{\circ}(\mathrm{SD})$ over the entire investigation.

Initial observations were made on spiders in boxes identical to their housing cages. Each individual had been food-deprived for up to 7 days. In this phase of our study we used the following types of prey: terrestrial isopods (Armadillidium sp.), 6-8 $\mathrm{mm}$; Japanese beetles (Popillia japonica), IO-I $2 \mathrm{~mm}$; mealworm larvae, $18-20 \mathrm{~mm}$; small grasshoppers (Cyrtacanthacridinae), 6-8 $\mathrm{mm}$; small ground crickets (Nemobiinae), IO- $13 \mathrm{~mm}$; and vestigial-winged fruit flies (Drosophila melanogaster), $2 \mathrm{~mm}$. We offered three prey at time $=0$, and additional single prey at $+\mathrm{Io}$ and $+20 \mathrm{~min}$ (all of the same species) in most of these tests. (For fruit flies, groups of eight were added at each of the three times.) Observation periods were at least $30 \mathrm{~min}$ in duration. The spider then was returned to its home cage with its captured prey.

To determine the functions of the various spinnerets in wrapping, we sealed pairs of spinnerets with paraffin while female $L$. rabida were under $\mathrm{CO}_{2}$ anesthesia. Two females underwent sealing of the anterior spinnerets; two had the anterior and median spinnerets sealed; and two, the median and posterior spinnerets. These spiders were subsequently observed and filmed (Bolex Macrozoom Super $8 \mathrm{~mm}$ camera, Model I6o) during prey-wrapping. We also examined the silk on the prey and substratum, after chasing away the female from her just-wrapped prey.

To study the preference of $L$. rabida (and, to some extent, $L$. punctulata) for the ground vs. the herbaceous stratum, we constructed artificial "field habitats" in three terraria $(0.2 \times 0.4 \times 0.2$ $m$ high). Cardboard "foliage" was fixed in a plaster base which provided the "ground surface" on $3 / 4$ of the terrarium bottom. The remainder of the glass bottom was left uncovered to provide an alternative ground surface in case the plaster had a repellent effect on the spiders (which turned out not to be the case). Vertical and sloping surfaces projecting into space were provided by the artificial foliage (Fig. I ). Spiders could climb to a height (limited by a glass lid) of $0.19 \mathrm{~m}$.

Three female $L$. rabida (tagged with non-toxic enamel) were housed in each terrarium. (Three individuals were cannibalized in the course of this experiment and were replaced with equivalently tagged substitutes.) To prevent possible conditioning effects, we fed the spiders on the ground as often as on the foliage. (Feeding was done at times other than the daily observation periods.) We observed the nine spiders for 2-hr blocks of time each day for Io days during 


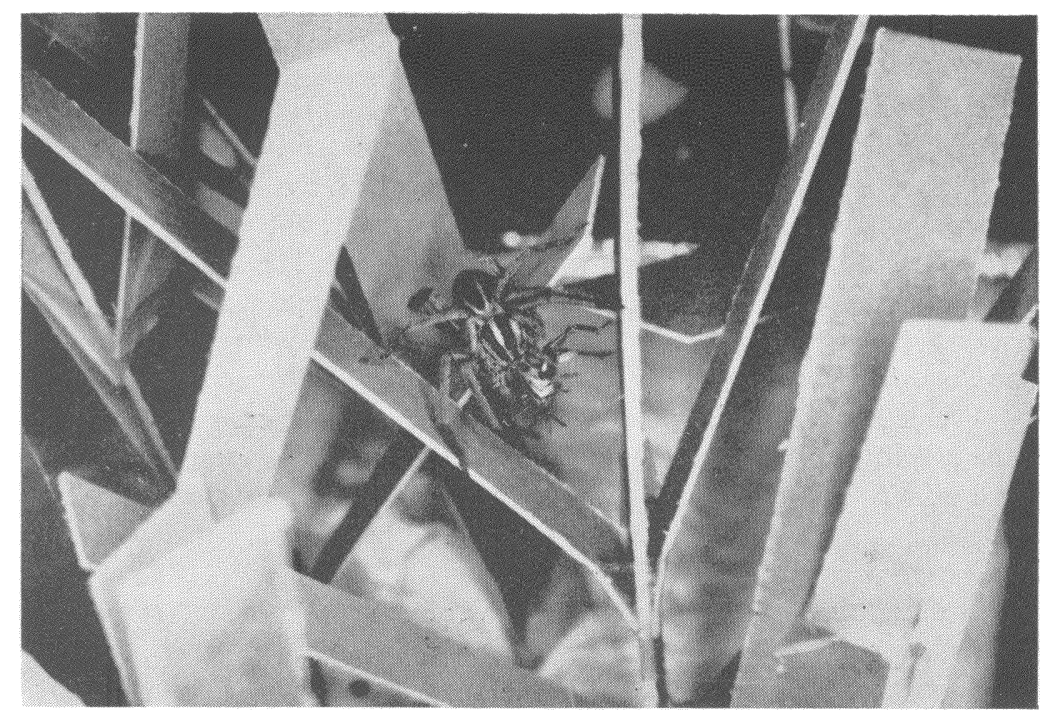

Fig. 1. Female Lycosa rabida (with prey) on artificial foliage.

the afternoon (on most days, I300-I500), and recorded the duration of time each spider spent on the ground vs. the foliage. At $1 / 2-h r$ intervals we also measured the height of those spiders that were on the foliage. After completing this phase of our study, we observed and filmed prey capture and wrapping by spiders on the artificial foliage. Analysis of these and other films was aided by use of a Bell \& Howell Super $8 \mathrm{~mm}$ Multi-motion projector.

Field observations were made on L. rabida during daylight hours (usually I300-1500), and during both day (I300-1500) and night (2030-2200) conditions on L. punctulata. The spiders were detected at a distance and their location within the habitat noted. By approaching carefully, we were able to film undisturbed $L$. rabida in the field.

\section{Prey-wrapping Behavior}

Whereas individuals of $S$. crassipes did not use silk after prey capture, those of $L$. rabida and, to a lesser extent, $L$. punctulata did so. In the latter two species, silk was not used to immobilize the prey, since wrapping began after the prey had ceased most of its struggling, usually several min after capture (Table I). 
Table I. Bouts of prey-wrapping by female Lycosa rabida (*) and Lycosa punctulata $(\dagger)$ when offered multiple prey during a 30 -min period. A total of 12 spiders was tested on each type of prey. (Sample sizes in parentheses.)

\begin{tabular}{lcccc}
\hline Prey & $\begin{array}{c}\text { Bouts/ } \\
\text { captures }\end{array}$ & $\begin{array}{c}\text { Mean } \\
\text { revolutions/ } \\
\text { bout }\end{array}$ & $\begin{array}{c}\text { Mean } \\
\text { duration } \\
(\mathrm{sec})\end{array}$ & $\begin{array}{c}\text { Mean onset } \\
\text { after bite } \\
\text { (min) }\end{array}$ \\
\hline *Mealworms & $16 / 40$ & $4.5(15)$ & $36(13)$ & $11.4(8)$ \\
*Grasshoppers & $28 / 27$ & $4.4(27)$ & $34(22)$ & $2.7(9)$ \\
*Crickets & $50 / 40$ & $3.2(48)$ & $26(39)$ & $1.1(8)$ \\
†Crickets & $6 / 32$ & $2.2(6)$ & $16(6)$ & $9.3(3)$ \\
\hline
\end{tabular}

When beginning a bout of wrapping, the spider spread and wiggled its spinnerets, flexed its abdomen ventrad, and then pressed its anterior spinnerets to the substratum. (Sometimes additional attachment disks were placed on the substratum in this manner within an arc of $60^{\circ}$ or less.) Then the spider began to pivot above the prey. In about $10 \%$ of the cases the spider pivoted $1 / 4$ revolution (or sometimes $1 / 2$ revolution), fixed an attachment disk to the substratum, and then began to turn in the opposite direction. However, in most cases the spider pivoted in only one direction, while remaining centered above the prey. During the first revolution, the silk was attached to the substratum at 2-5 points, the number perhaps depending on the prey's bulk. Fewer attachment disks were placed during the next turn or two, and usually only one or none during later revolutions.

During the first two or three turns, the spider usually held the prey in its chelicerae (Fig. 2). Consequently, as the spider revolved, the prey animals beneath it pivoted around with the spider. (Very large animals, while not held in the chelicerae during wrapping, and therefore not having their weight supported by the spider, were contacted by the palps, chelicerae, and sternum of the spider pivoting above.) If, as was the case with most prey, the spider held the prey in its chelicerae during early revolutions, it then released the prey during a subsequent turn and continued to pivot for one or more revolutions (Fig. 3). Throughout the process, the palps were used to contact or manipulate the prey. In L. rabida $80 \%$ of the wrapping bouts involved four or fewer revolutions (mean $=3.3 \pm 2.1 \mathrm{SD}$; range $\left.={ }_{\mathrm{I}-\mathrm{I} 4} ; n=106\right)$. Some views of one such bout are sketched in Fig. 4.

All three pairs of spinnerets were used during prey-wrapping. Data obtained from experimental animals indicated the same roles 


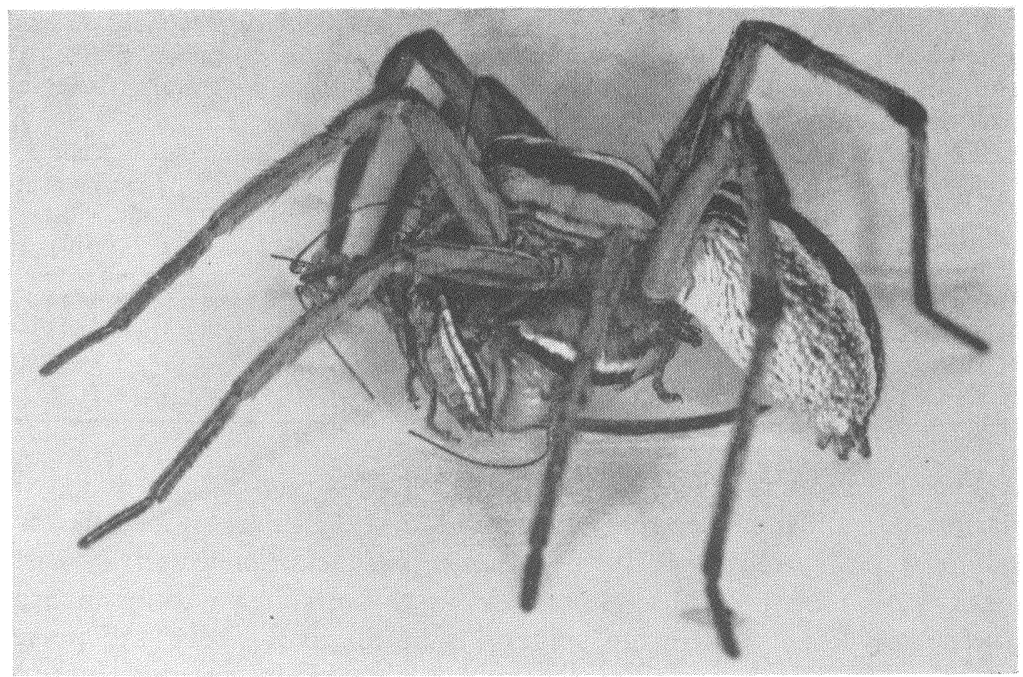

Fig. 2. Female Lycosa rabida placing an attachment disk on the substratum during the early phas? of prey-wrapping. The multiple prey are held in her chelicerae and palps.

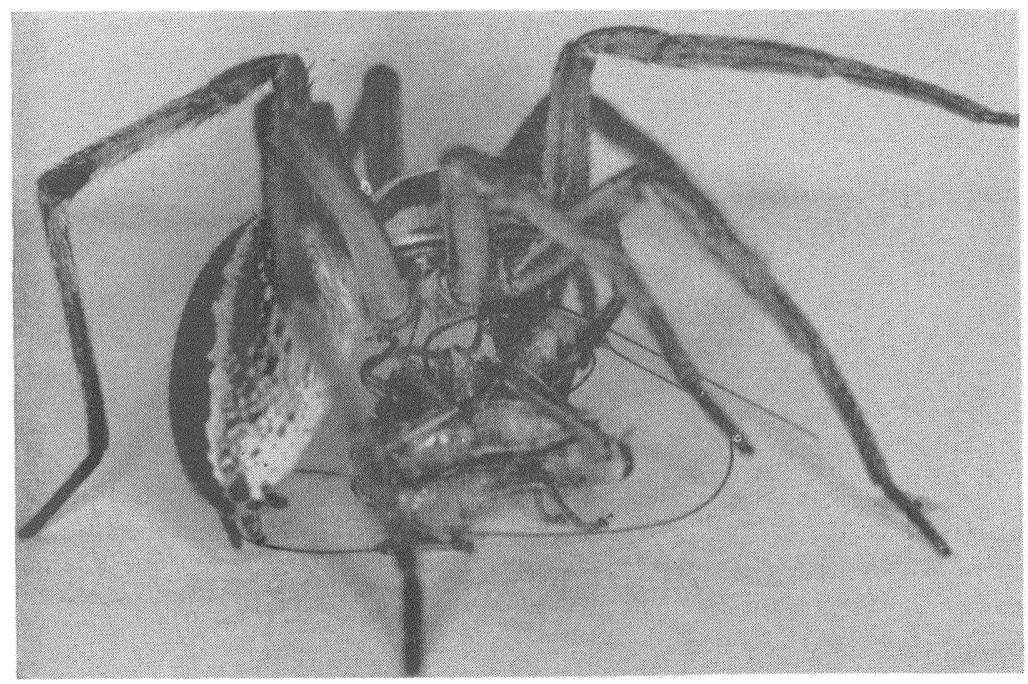

Fig. 3. Female Lycosa rabida during the later phase of prey-wrapping. The prey have just been released from her cheliceral grasp. (Her palps continue to contact the prey.) Swathing silk issues from her posterior spinnerets. 
for the spinnerets in lycosids as in other spiders that wrap prey. When the anterior spinnerets were sealed, no attachment disks were produced. The prey was wrapped but not fixed to the substratum. The same was true when the anterior and median spinnerets were sealed. When the median and posterior spinnerets were sealed, attachment disks were fixed to the substratum and dragline laid around the prey, but no swathing silk. In this case wrapping was not effective. Multiple prey were not tied together; indeed, the prey items were often pushed apart by the legs of the pivoting spider.

As the result of normal wrapping behavior, silk was placed around the bodies of the prey animals and attached to the substratum at intervals. Although the pivoting spider had pulled the threads taut, the silk was not dense enough to produce a very tightly wrapped package, as is produced by orb-weavers, for example. Indeed the wrapping was so sparse that it would be unnoticed by the casual observer. Nevertheless, the prey group did form a more compact mass than it had prior to wrapping. When the spider resumed feeding, it lifted the prey away from the substratum a short distance (rather than lean down to feed); however, the lines running to the substratum generally remained intact due to their elasticity.

After prey-wrapping, the spider sometimes groomed its chelicerae and palps, while remaining directly above the prey, and then resumed feeding. Additional prey that approached within reach were often captured; and one or more bouts of wrapping followed. However, regardless of whether further captures were made after the first bout of wrapping, subsequent bouts on the previously wrapped prey occurred later in the observation period in many cases.

Table II. Number of Lycosa rabida making single vs. multiple captures when offered multiple prey during a 30 -min period (second figure) and the number of those captures in which wrapping occurred (first figure). Twelve spiders of each sex were tested on each type of prey.

\begin{tabular}{|c|c|c|c|c|}
\hline \multirow[b]{2}{*}{ Prey } & \multicolumn{2}{|c|}{ Males } & \multicolumn{2}{|c|}{ Females } \\
\hline & $\begin{array}{l}\text { Single } \\
\text { capture }\end{array}$ & $\begin{array}{l}\text { Multiple } \\
\text { capture }\end{array}$ & $\begin{array}{c}\text { Single } \\
\text { capture }\end{array}$ & $\begin{array}{l}\text { Multiple } \\
\text { capture }\end{array}$ \\
\hline Isopods & $-/ 0$ & $--/ 0$ & $1 / 4$ & -10 \\
\hline Beetles & $0 / 1$ & $-/ 0$ & $2 / 6$ & -10 \\
\hline Mealworms & $0 / 9$ & $-/ 0$ & $1 / 3$ & $8 / 9$ \\
\hline Grasshoppers & 2/ 7 & $2 / 2$ & $1 / 1$ & $11 / 11$ \\
\hline Crickets & $0 / 4$ & $2 / 3$ & -10 & $12 / 12$ \\
\hline Totals & $2 / 21$ & $4 / 5$ & $5 / 14$ & $31 / 32$ \\
\hline
\end{tabular}


A
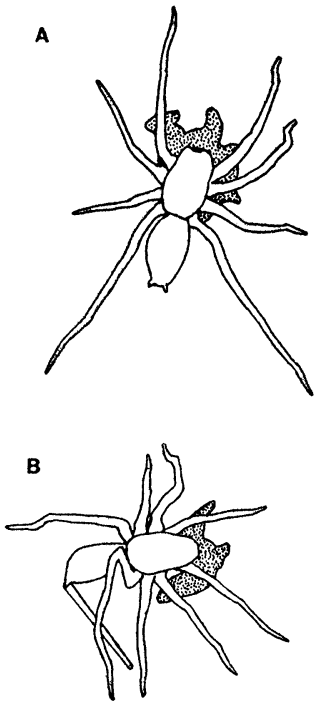

c

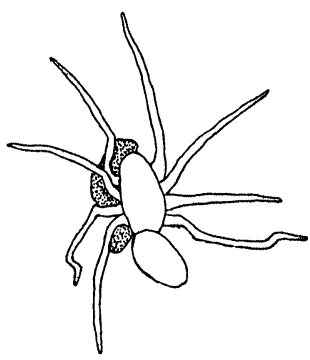

D

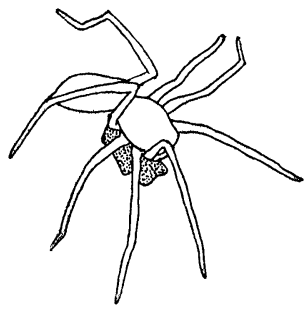

E
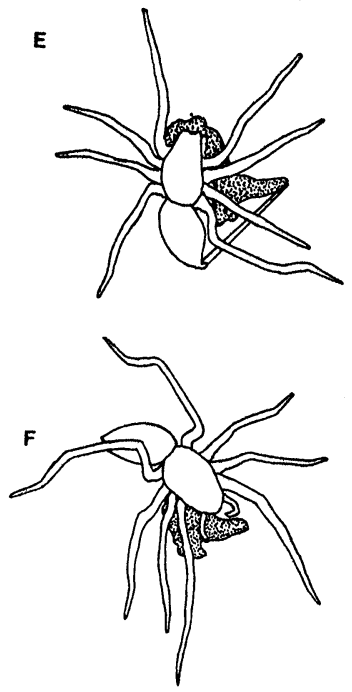

G

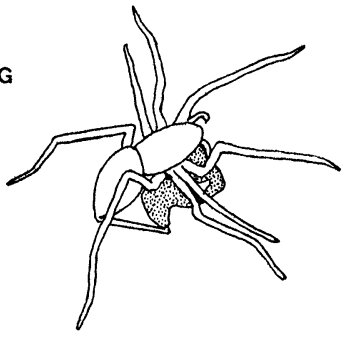

H

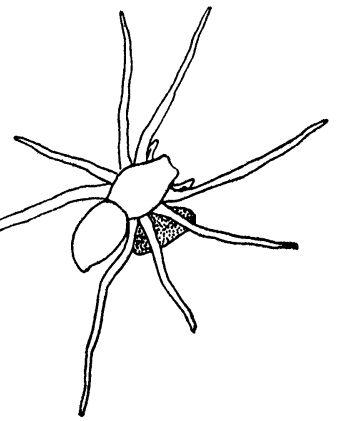


L. rabida wrapped various types of prey, especially in situations in which multiple prey were captured (Table II). While only $19 \%$ of the males captured multiple prey, $68 \%$ of the females did so. Considering both sexes together, wrapping occurred in $20 \%$ of the cases in which only single captures were made, and in $95 \%$ of the cases in which two or more prey were captured. Such correlations meant that females wrapped prey much more often than males, performing at least one bout of wrapping in $78 \%$ of the observation periods in which they captured prey (single or multiple), while males did so only $23 \%$ of the time. None of our spider species wrapped fruit flies.

As shown in Table I, individuals of $L$. punctulata wrapped prey much less often than L. rabida and did so less intensively (fewer turns and shorter bout duration). Furthermore, it was only four of the twelve females that did so; none of the twelve males wrapped prey.

\section{Stratum Selection}

Field observations. - We watched penultimate and adult $L$. rabida on sunny, calm days (early July) in a grassy field near the edge of a woods. Undisturbed individuals rested motionless on the leaves and stems of grasses and other vegetation. The spiders typically were on horizontal or sloping surfaces (rather than vertical ones). Those individuals we happened to observe were on the upper leaves of relatively low vegetation or part-way up the stems and leaves of taller vegetation.

In response to mild disturbance, the spiders walked or climbed a short distance and then resumed their motionless stance. Strong disturbance (as that which resulted from our walking near them during our collecting efforts) caused the spiders to run and climb

Fig. 4. [Opposite page]. Sketches, based on a Super $8 \mathrm{~mm}$ film, showing dorsal views of prey-wrapping by a female Lycosa rabida. The several items of the multiple prey-capture are drawn as an homogenous mass (stippled) for convenience, and should not be regarded as a wrapped bundle. Lighting conditions permitted seeing the silk in views $B, E$, and G. Times were rounded to the nearest sec. A. Placing 1st attachment disk $($ Time $=0)$. B. One-quarter into the 1 st revolution $(+4 \mathrm{sec})$. C. Near end of 1 st revolution $(+7 \mathrm{sec})$. D. One-third into 2 nd revolution $(+9 \mathrm{sec})$. E. Near end of 2 nd revolution $(+12 \mathrm{sec})$. Prey were released from the chelicerae at the beginning of the next revolution. F. One-third into $3 \mathrm{rd}$ revolution $(+14 \mathrm{sec})$. G. Beginning of 4th revolution $(+18 \mathrm{sec})$. $H$. End of 4th and final revolution $(+21 \mathrm{sec})$. 
swiftly through the foliage, sometimes breaking into a series of leaps and dashes that carried them long distances along the top of lowgrowing vegetation in a few seconds. Thus, these animals usually remained in the herbaceous stratum; only occasionally did an individual plunge downward and hide near the ground.

Penultimate $L$. punctulata were seen in the fall in the same fields, and typically traveled through the herbaceous stratum when disturbed. At night these spiders were seen resting on or moving slowly upon the vegetation or, much less frequently, upon the ground.

Laboratory studies. - The results of our study of diurnal stratum selection by undisturbed female $L$. rabida in an artificial habitat are summarized in Fig. 5. (Temperature was $25-26^{\circ}$ and relative humidity $>60 \%$ throughout the IO days.) During the 20-hr survey, the spiders were on the cardboard foliage $73 \%$ of the time. Most of that time the animals rested motionless on one of the "leaves" at an average height of $0.12 \mathrm{~m}$, i.e., more than half-way up the "plant." The long axis of their bodies was usually in a plane ranging from nearly horizontal to a slope of about $60^{\circ}$ from the horizontal. In the latter situation the spider faced up- or downward. In those cases in which the spider rested vertically on a "stem" the spider

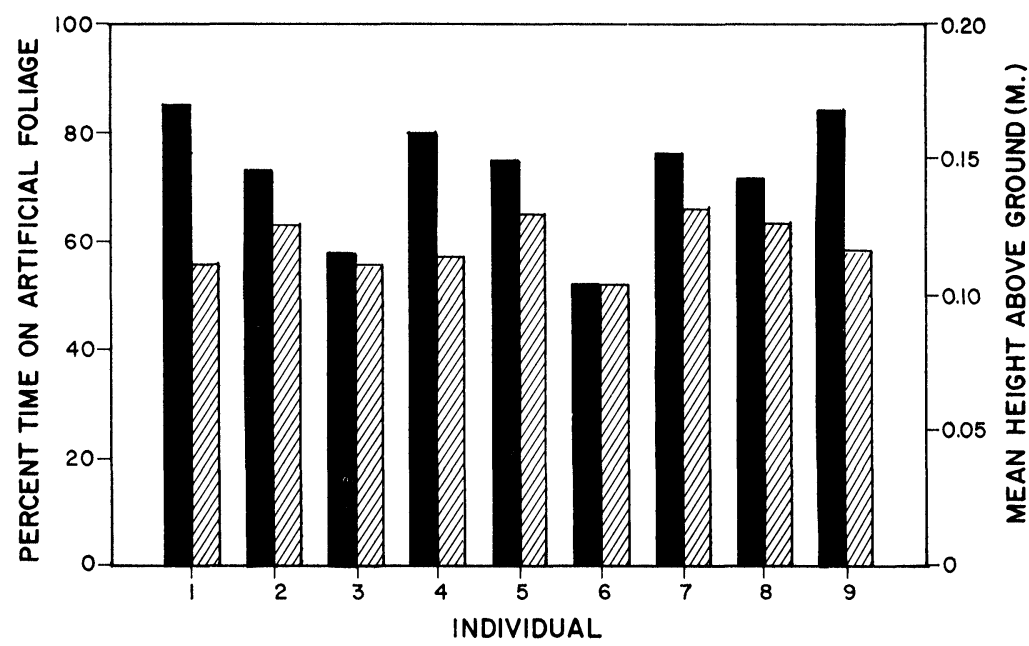

Fig. 5. Stratum selection by female Lycosa rabida in an artificial habitat. During $20 \mathrm{hr}$, spread over 10 days, we recorded the proportion of time spent on cardboard foliage (solid bar) vs. on the ground. At halfhr intervals within observation periods, we also measured the height of those spiders that were on the foliage (hatched bar). 
typically faced downward. Individuals rested more often in an upright position on the upper surface of the leaf (illumination = approx. 400 lux) than they did in an inverted position beneath the leaf (illumination $=$ approx. I 30 lux).

We considered each spider's behavior within the 2-hr periods of observation and noted that each remained within the "herbaceous stratum" during the entire $2 \mathrm{hr}$ in 5.3 (range $=4-7$ ) of the ten periods. Each spider remained on the ground throughout the 2-hr period in only 1.6 (range $=0-3$ ) of the ten periods. The spider moved from the ground to the foliage or vice versa in the remaining 3.I (range $=2-4$ ) of the ten periods.

Some observations made on several female $L$. punctulata in the artificial habitat indicated that these spiders also tended to spend their time resting on the foliage. However, we did not quantify this part of our study.

After completing the IO-day survey of stratum selection by $L$. rabida, we observed and filmed prey-wrapping by these spiders on the artificial foliage. The behavior resembled that performed on the floors of the housing containers, as we described above. Wrapping

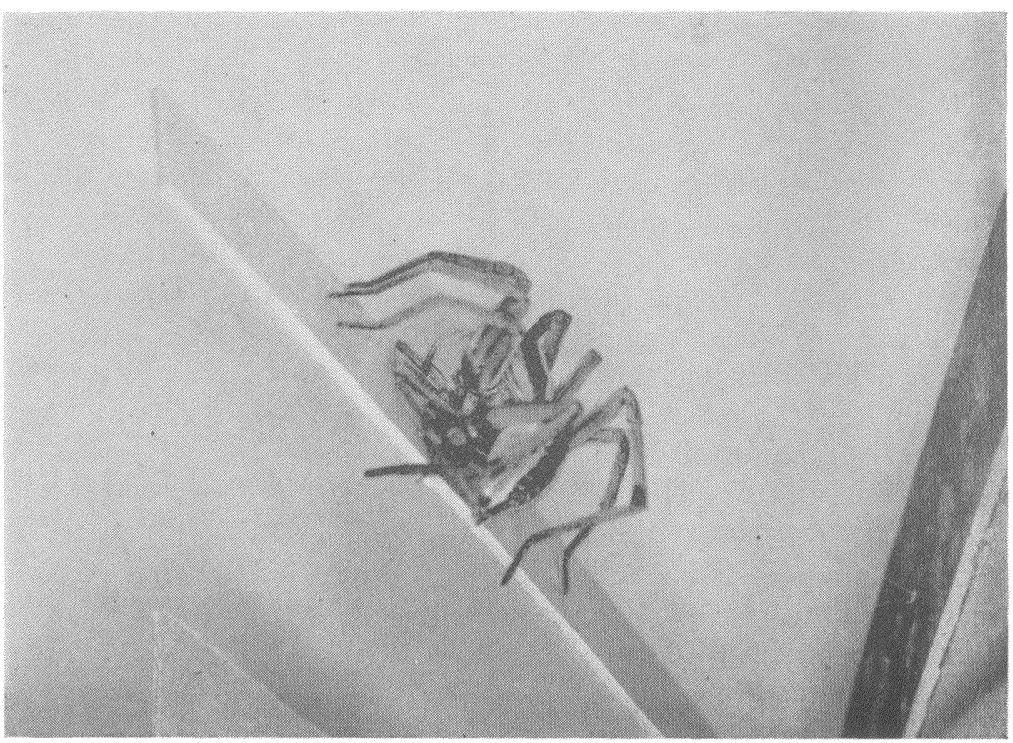

Fig. 6. Female Lycosa rabida wrapping prey on artificial foliage. This leaf sloped at an angle of about $60^{\circ}$ to the horizontal. 
usually was performed at the capture site and therefore was carried out in all planes, including the vertical. The spiders behaved on sloping leaves and vertical stems in a manner similar to that seen on the horizontal cage floors; however, pivoting was slower on the narrow surfaces, apparently due to the spider's having to seek footholds as it revolved "above" the prey (Fig. 6).

In some cases, we intentionally disturbed the spider before or after prey-wrapping. In the former situation, the prey sometimes was released from the chelicerae and dropped to a lower leaf or to the ground. On the other hand, if wrapping already had occurred, they prey did not fall from the capture site when released from the chelicerae, even on a vertical surface. When multiple prey were wrapped on a sloping surface, they: (I) remained together rather than roll apart and (2) hung at the wrapping site rather than drop to the ground, when the spider was chased away.

A further bit of evidence for the adaptedness of $L$. rabida to the herbaceous stratum was provided later by the construction of a "shelter web" (about $50 \mathrm{~mm}^{3}$ ) and, within it, an egg sac (infertile) by a female on a nearly horizontal leaf $0.13 \mathrm{~m}$ above the ground in the artificial habitat.

\section{Discussion}

Preference for herbaceous stratum. $-\mathcal{S}$. crassipes is well-known as an inhabitant of woodland leaf-litter (Kaston, 1948; Fitch, 1963); indeed, lycosids are generally regarded as ground-dwellers (Lowrie, 1968). However, L. rabida and L. punctulata can be collected by sweeping grass and shrubs (Kaston, 1948). Kuenzler (1958) also found $L$. rabida on the lower trunk and branches of trees in open woodland. Whitcomb et al. (1963) describe finding L. rabida in cotton fields on the ground during the day, but at night ". . . halfway up the cotton stalks feeding on bollworm or cabbage looper moths . . ." as well as on noctuid moths. At night, Eason and Whitcomb (1965) collected $80 \%$ of their specimens of L rabida $2 / 3 \mathrm{~m}$ or more above the ground in tall grass and bushes.

According to Eason and Whitcomb (1965), "L. punctulata is mostly captured on or near the ground, since it has less tendency to climb into bushes than does $L$. rabida." While finding both species in grassland, Fitch (1963) reported that L. punctulata preferred ". . . relatively open or barren situations as compared to L. rabida, which prefers a tall-grass habitat." Kaston (1948) stated simply that both species have the same habits. 
Our field and laboratory observations are in agreement with the general idea expressed above $-L$. rabida and $L$. punctulata are adapted for spending a significant part of their life in the herbaceous stratum, rather than being, like most lycosids, ground-dwellers. (Obviously, stratum selection may vary during the life of an individual under different conditions, both external (temperature, humidity, wind, etc.) and internal (hunger, sexual state, etc.)). A difference between the species in regard to habitat or stratum selection, suggested by some authors, was not examined by us, but might be revealed by quantitative field and laboratory studies. The relatively longer legs of $L$. rabida suggests a greater adaptation to the herbaceous stratum than that of $L$. punctulata, as does the stronger tendency of $L$. rabida to wrap prey.

While these lycosids are often seen running about, perhaps migrating from one habitat to another in response to micro-climatic conditions, or perhaps merely reacting to the collector's movements, most of their time is probably spent at rest on the foliage. This seemed to be the case in the field, and was certainly the situation in the artificial habitat. As has been noted elsewhere (Edgar, 1969), lycosid spiders generally remain motionless and wait for their prey to come within reach. Like the web-weaving spiders, the wandering spiders of the herbaceous stratum are resting on a medium that provides effective transmission of vibrational cues from the prey.

Function of prey-wrapping. - We hypothesize that post-immobilization prey-wrapping in $L$. rabida and $L$. punctulata is a behavioral adaptation for life in the herbaceous stratum. It reduces the possibility of losing the prey items when the spider releases them from its cheliceral grasp between bouts of feeding. The spider may release its grasp to make an additional capture, to groom, to drink, or to locate another point on the prey's body for further feeding. Also, when startled by another animal or by shaking of the substratum due to wind, the spider's momentary release of the prey would often result in its loss. No such problem exists for grounddwelling forms.

Our hypothesis is supported by the absence of wrapping after the capture of small prey, which are easily held in the chelicerae and ingested in a relatively short time. It appears, then, that post-immobilization wrapping serves the same primary function in wandering spiders as it does in web-weavers - to prevent the prey from dropping to the ground from the spider's elevated location. Also, it is important when multiple prey are captured by a wandering spider, 
since the number of prey that the spider can hold in its chelicerae during feeding is limited.

As to the functions of the components of prey-wrapping, we suggest the following. The swathing silk serves to enclose the prey, a role that is not only important for holding multiple prey together, but which is also of value in holding together the pieces that often result from the process of ingesting a single prey item. This latter function may be one reason for the occurrence of additional bouts of wrapping during the course of feeding. The dragline may be entangled in the swathing band and serve to attach the prey package to the substratum via the attachment disks, although it seemed that the swathing band itself was connected to the attachment disks. Since attachment to the substratum seems to be of prime value in preventing loss of acquired food material, the re-anchoring that occurs in additional wrapping bouts during the course of feeding probably makes up for the breakage of lines that accompanies the physical and chemical processing of the prey by the feeding spider, and thus may be another reason for extra bouts of wrapping.

The temporal pattern is one of providing multiple attachment points, along with swathing, during the early phase of each bout (while the prey is held in the chelicerae) and then devoting most of the remaining time to swathing (after the prey has been released from the chelicerae). The early phase (attachment) may be important for effective wrapping, since it enables the spider to release the prey and pivot around it, pulling the swathing lines taut.

Role of aciniform and other silk glands. - Comstock (I9I2) and others have described the aciniform glands of web-weaving spiders as the source of the swathing silk used for prey-wrapping, as well as the fine fibers of egg sacs. These glands are present in lycosids, but their function had remained unknown (Richter and Van der Kraan, 1970). On the basis of histological data, Richter ( $1970 a$ ) suggested roles for the aciniform glands in lycosid spiders - in producing silk involved in molting, egg sac construction, and sperm web construction.

Our data indicate that the aciniform glands also have one of the same functions in lycosids as they do in the web-weavers - production of swathing silk for wrapping prey. When the spigots for these glands were closed experimentally (by sealing the median and posterior spinnerets), wrapping behavior was ineffective. Such spiders pivoted, fixed attachment disks, and laid a dragline; however, no broad bands of silk were placed on the prey. Indeed, the several items of multiple prey were often pushed apart by the legs of the pivoting spider. 
Our sealing of the anterior spinnerets (site of spigots for the piriform glands) prevented attachment disk production, as was wellknown in the literature. Such spiders could wrap the prey but not attach it to the substratum. This was also the case with spiders that had their anterior and median spinnerets sealed, with the further limitation of being incapable of producing draglines. In summary, for complete wrapping of the prey, these lycosids are using all three pairs of spinnerets and employing silk from three types of silk glands (the third being the ampullaceal glands - for production of draglines - whose spigots are on the anterior and median spinnerets). This agrees with observations made by Melchers (196I) on preywrapping by normal individuals of Cupiennius salei, a large ctenid spider.

Since the wrapping of prey by lycosids (and at least some other wandering spiders) probably correlates with a preference for the herbaceous (or higher) stratum, we hypothesize that the size of the aciniform glands, source of swathing silk, would also. This expectation is based on Richter's ( $1970 b$ ) demonstration of such a correlation between ampullaceal gland size (dragline silk) and preferred vegetation structure in Pardosa spp. Indeed, we should expect lycosids with larger ampullaceal glands to have larger aciniform glands, based on our hypothesis and on Richter's findings.

Stimuli releasing prey-wrapping. - The correlation between the frequencies of prey-wrapping and multiple prey-capture suggests that the latter event provides a stimulus situation to release prey-wrapping. The value of wrapping for retaining multiple prey has been discussed above. However, wrapping certainly occurs after single prey are captured, if these prey are about as large or larger than the spider's body size. It seems, then, that the stimulus for post-immobilization wrapping is that of a relatively large volume or mass of prey material beneath the spider, not the absolute number of prey captured. We suspect volume rather than weight to be the stimulus, since very large prey are wrapped without being held in the chelicerae following a capture in which the bite was maintained without the spider supporting the weight of the prey resting on the substratum.

Prey-wrapping was initiated after the prey had ceased most or all of its struggling. Groups of small crickets or grasshoppers, each member of which succumbed quickly to the spider's bite, were wrapped within a minute or two after capture. Mealworms, which performed active twisting of the free end of their body for a long time, were not wrapped until about Io min after capture. Very 
large, single prey were wrapped only after a lengthy period, $\mathrm{I}$ hr or more, had elapsed. It appears that the absence of vigorous movements by the prey is a necessary part of the stimulus situation for the onset of wrapping.

Post-immobilization wrapping in other wandering spiders. - Our two species of $L y \cos a$ performed post-immobilization wrapping, whereas Schizocosa crassipes did not. We modified our original speculation that this behavior might be characteristic of the Lycosidae to the notion that it might be at least genus-specific. Even this is no longer tenable, in light of our preliminary observations on other species as well as data obtained by R. J. McKay (personal communication). We now regard post-immobilization prey-wrapping as a behavioral adaptation that may be included in the repertoire of various unrelated wandering spiders that have specialized for spending part or most of their time some distance above the ground on vegetation.

Post-immobilization wrapping occurs after the prey has stopped struggling, occupies a relatively brief amount of time during the lengthy feeding process, and is used for prey only when the total volume exceeds some threshold value. These are the probable reasons why this behavior has not yet been reported in many species in which it is likely to occur. Authors specifically studying feeding behavior have seen post-immobilization wrapping in two other families of wandering spiders - ctenids (Melchers, 1961, 1963) and theraphosids (Eberhard, 1967), although neither of these authors determined the function.

A personal communication from E.-A. Seyfarth, that wrapping occurred in Cupiennius salei, called our attention to the work of Melchers (1961, I963) on this ctenid species. (Comparison with our species was facilitated by our being able to view Melchers' (I96I) film of this behavior.) Post-immobilization wrapping by $C$. salei is very similar to what occurs in our $L y \cos a$ spp. as to the sequence of events and movements, stimuli releasing the behavior, etc. However, two differences are obvious: (I) C. salei waits for prey on a vertical surface. If it tumbles to the ground during prey capture, it carries the prey back up to an elevated point on the vertical surface - the glass wall of the terrarium in Melchers' study. Individuals of our species never did the latter, but readily stayed on the ground to feed if the capture ended there. (2) The density and breadth of the swathing bands are much greater in $C$. salei than in our Lycosa spp. Points $I$ and 2 are probably interrelated and suggest that this ctenid 
spider is even more specialized for living on vegetation than are our Lycosa spp.

Scopula hairs, which enable spiders to climb smooth surfaces, have been studied in lycosids, theraphosids, and other wandering spiders (Foelix and Chu-Wang, 1974). Since these structures are an important adaptation for many of the spiders which spend their life on vegetation, they may serve as a morphological indicator of behavioral correlates of this life style, including post-immobilization prey-wrapping. Indeed, a scopula is present in those species in which this behavior has been seen. On the other hand, since scopula hairs on the tarsus and metatarsus are probably important for the capture and manipulation of prey (Rovner and Knost, in preparation), their presence may not always be indicative of habitat preference and related behaviors.

Experimentally modified male L. rabida that are unable to achieve palpal insertions "tie-down" females during attempted copulation (Rovner, I97I), a behavior resembling post-immobilization wrapping of large prey. Male thomisid spiders perform a similar behavior as part of their normal pre-copulatory activity. (In neither case does the wrapping have any restraining effect on the female, who easily tears the threads and departs when the copulation is completed.) Perhaps the pre-copulatory wrapping in thomisids is a ritualized behavior derived from a present or past use of silk for wrapping prey in this family.

Eberhard (1967) associated post-immobilization wrapping with certain primitive types of aerial web-building, similar to that exhibited by the present-day diguetid spiders. The behavior shown by our Lycosa spp. of the herbaceous stratum, and by other wandering spiders, suggests that the evolution of post-immobilization wrapping may not be as closely associated with the building of aerial webs as Eberhard had hypothesized.

\section{SUMMARY}

Post-immobilization wrapping of large, single prey and groups of smaller prey occurs in Lycosa rabida and, to a lesser extent, $L y \cos a$ punctulata. Observation of these spiders in both the natural habitat and an artificial habitat indicated their preference for the herbaceous stratum. Post-immobilization wrapping is probably an adaptation for life in this stratum, since it reduces the possibility of losing prey when it is released from the cheliceral grasp. The swathing bands, attachment disks, and draglines involved in wrapping are produced 
with silk from the aciniform, piriform, and ampullaceal glands respectively. Post-immobilization prey-wrapping, well-known in webweavers and now known in ctenids, lycosids, and theraphosids, is likely to be found in other wandering spiders that live on foliage.

\section{Literature Cited}

Сомsтоск, J. H.

1912. The Spider Book. Garden City, N. Y.: Doubleday, Page. 725 pp.

EASON, R. AND W. H. Whiтcomb

1965. Life history of the dotted wolf spider, Lycosa punctulata Hentz (Araneida: Lycosidae). Proc. Arkansas Acad. Sci. 19: 11-20.

EBERHARD, W.

1967. Attack behavior of diguetid spiders and the origin of prey wrapping in spiders. Psyche 74: 173-181.

EDGAR, W. D.

1969. Prey and predators of the wolf spider Lycosa lugubris. J. Zool., Lond. 159: 405-411.

FITCH, H. S.

1963. Spiders of the University of Kansas Natural History Reservation and Rockefeller Experimental Tract. Misc. Publ., Mus. Nat. Hist., Univ. Kansas 33: 1-202.

Foelix, R. F. and I. W. Chu-Wang

1974. Scopula hairs in spiders. Proc. Sixth Int. Congr. Arach. In press.

Kaston, B. J.

1948. Spiders of Connecticut. Bull. State Geol. Natur. Hist. Surv., Hartford $70: 1-874$

KUeNZLeR, E. J.

1958. Niche relations of three species of lycosid spiders. Ecology 39: 494-500.

LOWRIE, D. C.

1968. The spiders of the herbaceous stratum of the Jackson Hole region of Wyoming. Northwest Sci. 42: 89-100.

Melchers, M.

1961. Cupiennius salei (Ctenidae) Einspinnen der Beute und Nahrungsaufnahme. Encycl. Cinemat., E 421.

1963. Zur Biologie und zum Verhalten von Cupiennius salei (Keyserling), einer amerikanischen Ctenide. Zool. Jahrb. Abt. System. 91: $1-90$.

Richter, C. J. J.

1970a. Morphology and function of the spinning apparatus of the wolf spider Pardosa amentata (Cl.) (Araneae, Lycosidae). Z. Morph. Tiere 68: 37-68.

1970b. Relation between habitat structure and development of the glandulae ampullaceae in eight wolf spider species (Pardosa, Araneae, Lycosidae). Oecologia (Berl.) 5: 185-199.

Richter, C. J. J. ANd C. VAN Der KraAN

1970. Silk production in adult males of the wolf spider Pardosa amentata (Cl.) (Araneae, Lycosidae). Neth. J. Zool. 20: 392-400. 
Robinson, M. H., H. Mirick, and O. Turner

1969. The predatory behavior of some araneid spiders and the origin of immobilization wrapping. Psyche 76: 487-501.

ROVNER, J. S.

1971. Mechanisms controlling copulatory behavior in wolf spiders (Araneae: Lycosidae). Psyche 78: 150-165.

RovNer, J. S. AND S. J. KNOST

Prey capture by lycosid spiders. In preparation.

Whitcomb, W. H., H. Exline, and R. C. Hunter

1963. Spiders of the Arkansas cotton field. Ann. Ent. Soc. Amer. 56: 653-660.

ERRATUM. - In our paper on "Social Carrying Behavior and Division of Labor During Nest Moving in Ants", Psyche, Vol. 8I, No. 2, pages 219-236, the last line of the caption of Fig. Io should read: Dotted Line: Formica sanguinea; Solid Line: Camponotus sericeus. - Michael Möglich and Bert Holldobler (Biological Dept., MCZ-Laboratories, Harvard University). 

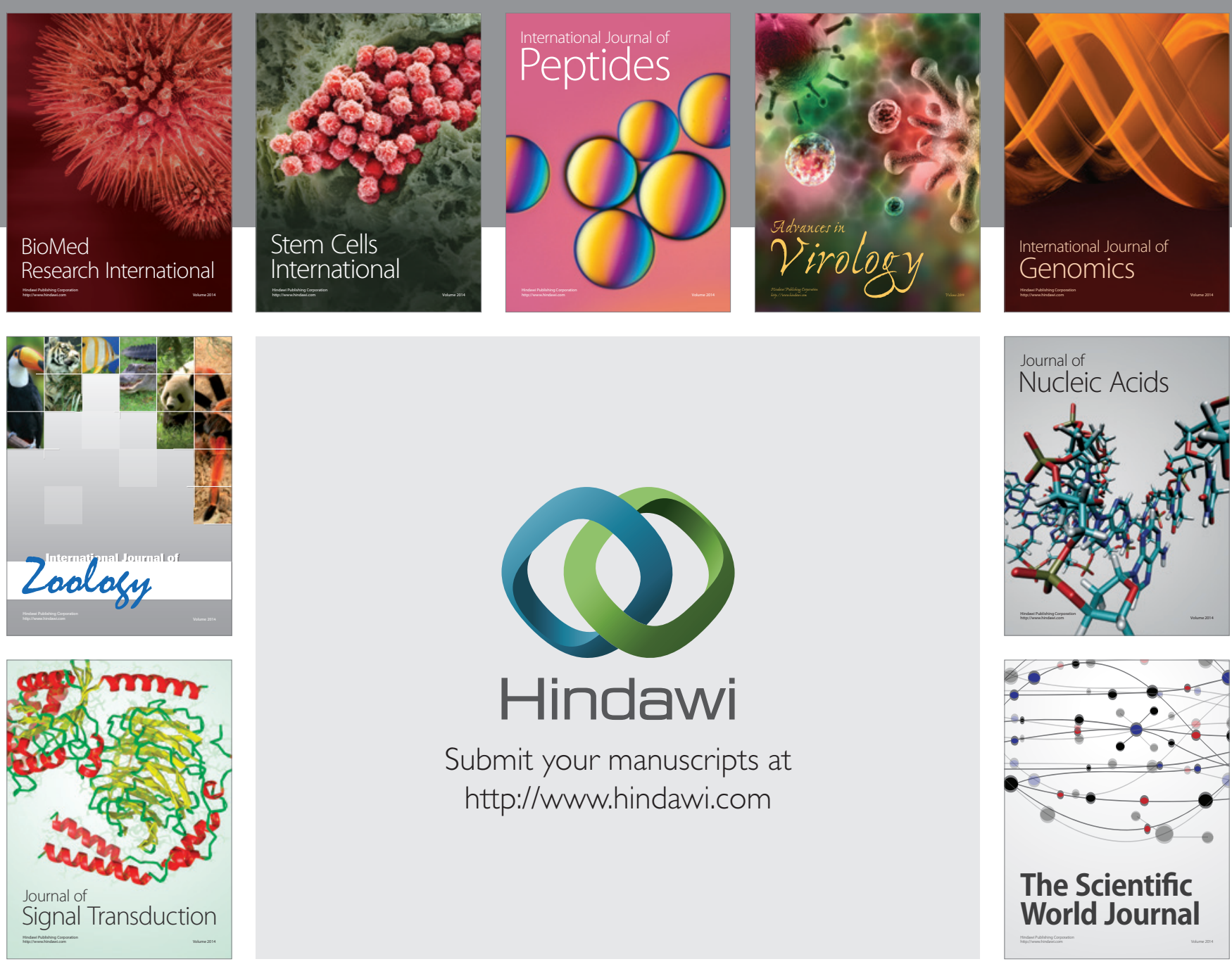

Submit your manuscripts at

http://www.hindawi.com
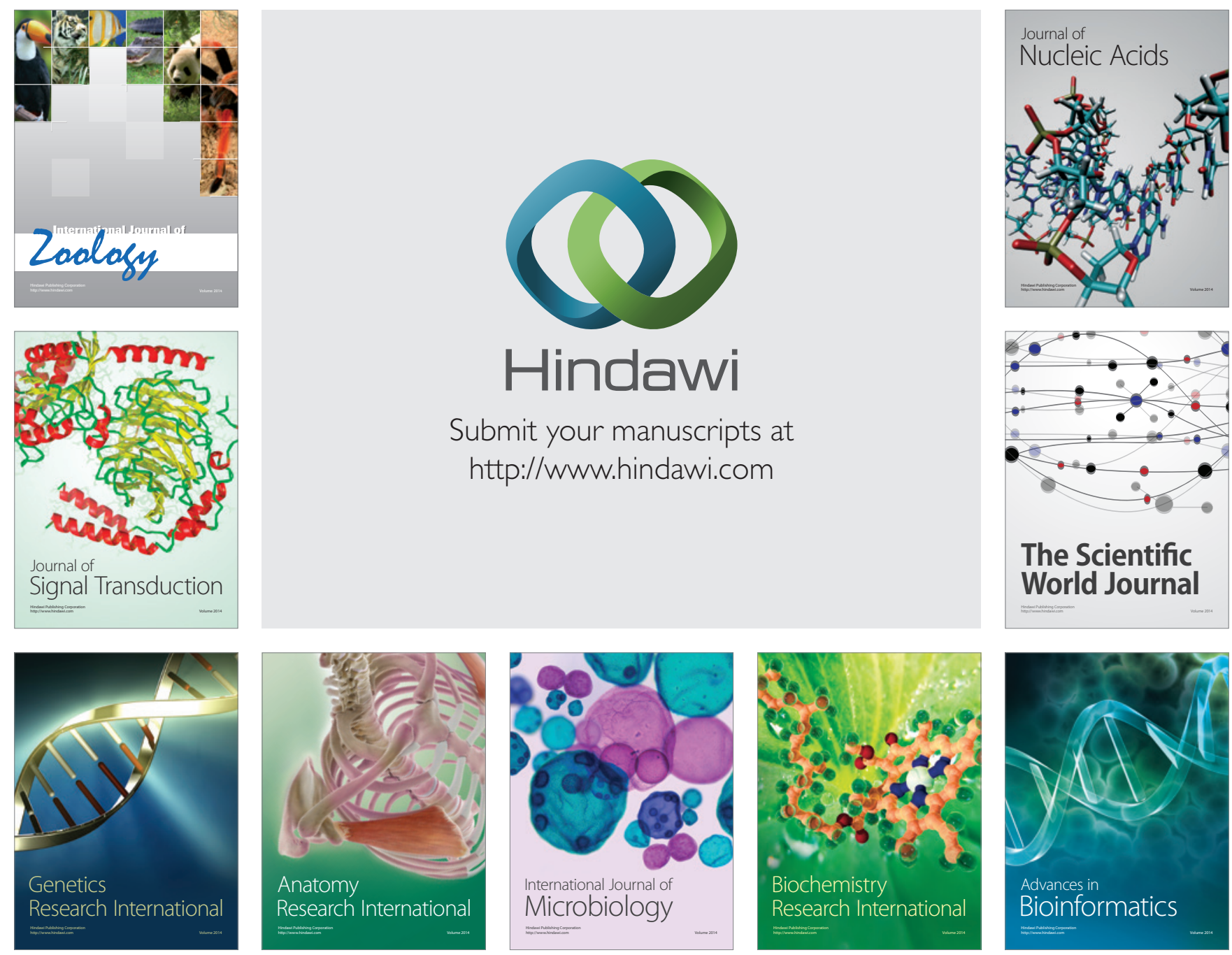

The Scientific World Journal
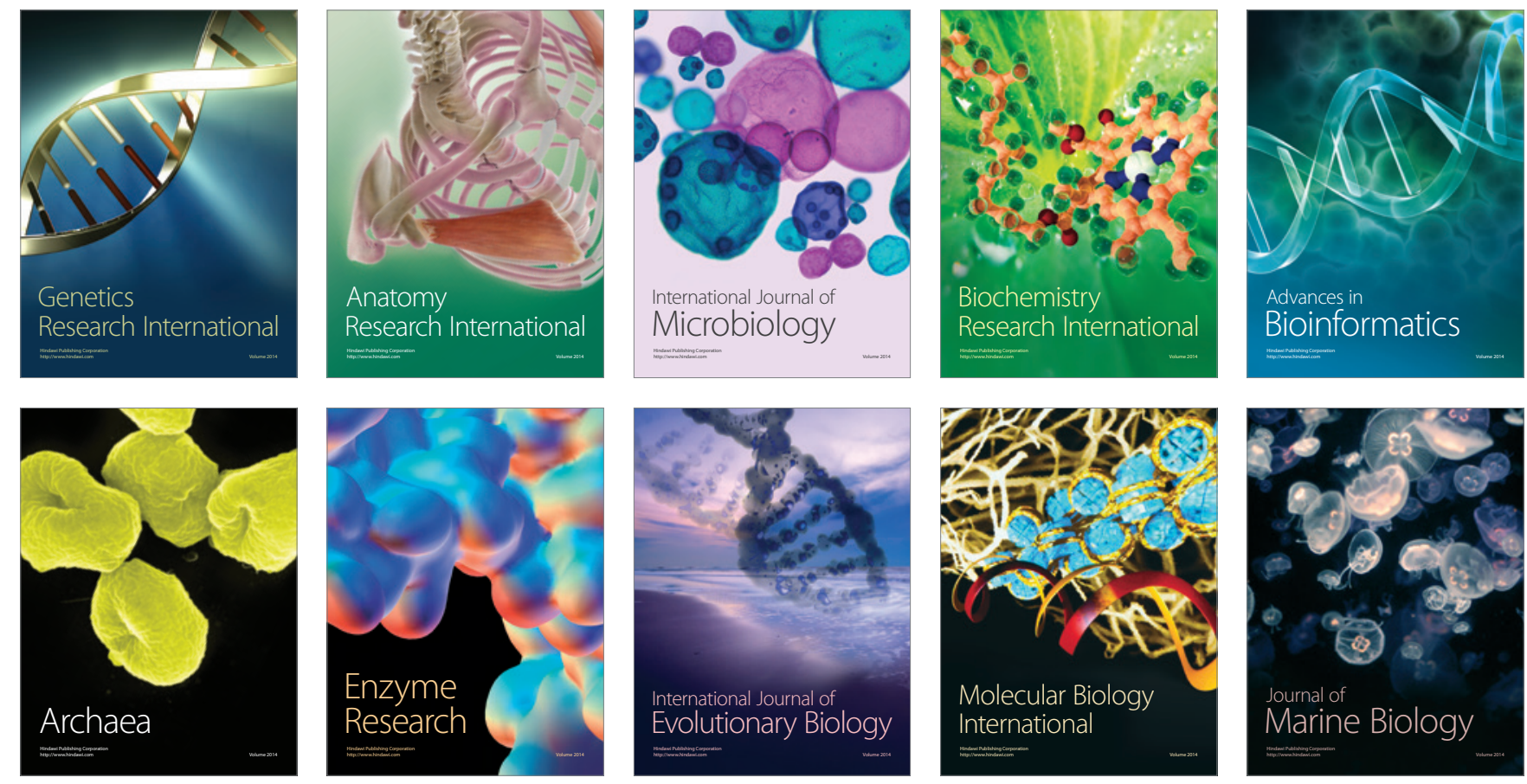